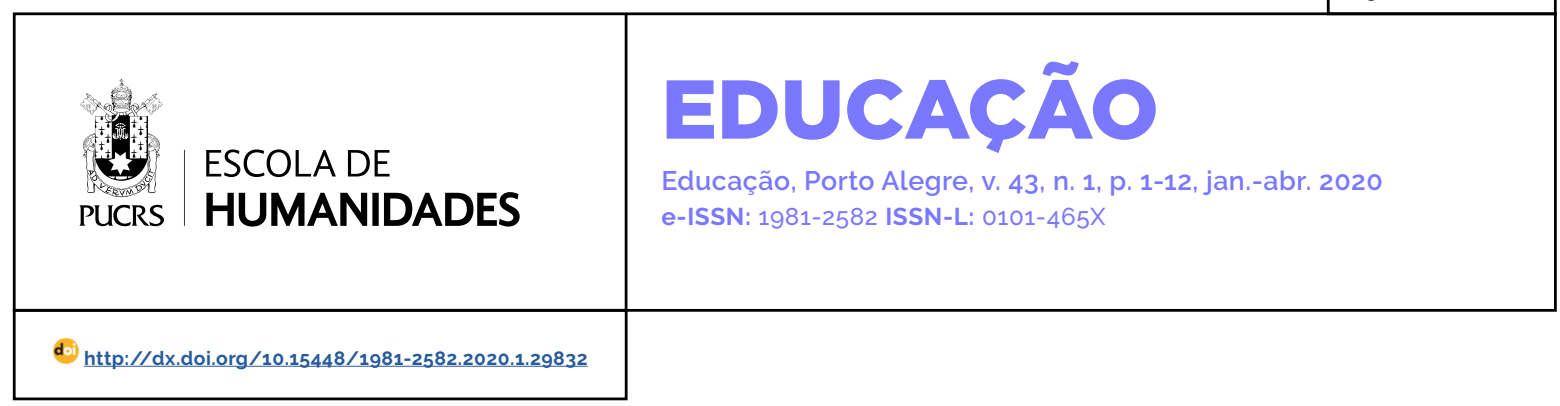

OUTROS TEMAS

\title{
Considerações de natureza epistemológica sobre a análise textual discursiva
}

\author{
Epistemological nature considerations about the discursive textual analysis \\ Consideraciones de naturaleza epistemológica sobre el análisis textual discursivo
}

Fábio Peres Gonçalves ${ }^{1}$ orcid.org/0000-0003-0172-2411 fabiopgon@hotmail.com

Recebido em: 29 jan. 2018. Aprovado em: 20 nov. 2019. Publicado em: 25 mai. 2020.
Resumo: Este trabalho examina como a análise textual discursiva pode ser caracterizada nas discussões epistemológicas associadas à possibilidade do conhecimento. Sinaliza-se que há pressupostos teóricos na análise textual discursiva, na qualidade de um procedimento analítico, que a distanciam de uma perspectiva relativista. Por conseguinte, averigua-se a necessidade de as pesquisas em Educação em Ciências, em particular, e em Educação, em geral, que adotam esse procedimento analítico, apoiarem-se em interlocutores teóricos que se afastem igualmente do relativismo. Essa defesa é coerente com a ideia de reconhecer a análise textual discursiva como um procedimento analítico, mas sem reduzi-lo a um puro conjunto de passos a serem seguidos na análise de informações qualitativas.

Palavras-chave: análise textual discursiva, pesquisa qualitativa, educação, educação em ciências.

Abstract: This paper examines how the discursive textual analysis can be characterized in epistemological discussions associated with the possibility of knowledge. It indicates that there are theoretical assumptions in the discursive textual analysis, in the quality of an analysis method, that distances itself of a relativistic perspective. Therefore, this ascertains the need for research on Scientific Education, in particular, and research in Education in general, which adopt this method, support in theoretical interlocutors that depart also of relativism. This defense is consistent with the idea of recognizing the discursive textual analysis as an analytical method, but without reducing it to a pure set of steps to be followed in the analysis of qualitative information.

Keywords: discursive textual analysis, qualitative research, education, science education.

Resumen: Este trabajo examina cómo el análisis textual discursivo puede ser caracterizado en las discusiones epistemológicas asociadas a la posibilidad del conocimiento. Se señala que hay presupuestos teóricos en el análisis textual discursivo, en la cualidad de un procedimiento analítico, que lo distancian de una perspectiva relativista. Se averigua, por lo tanto, la necesidad de que las investigaciones en Educación en Ciencias, en particular, y en Educación, en general, que adoptan ese procedimiento analítico, se apoyen en interlocutores teóricos que se alejan igualmente del relativismo. Esta apelación es coherente con la idea de reconocer el análisis textual discursivo como un procedimiento analítico, pero sin reducir éste a un mero conjunto de pasos a ser seguidos en el análisis de informaciones cualitativas.

Palabras clave: análisis textual discursivo, investigación cualitativa, educación, educación en ciencias. 
Encontram-se na literatura trabalhos que caracterizam os aportes epistemológicos de "instrumentos analíticos" utilizados na pesquisa em Educação em Ciências. Mortimer, Scott e El-Hani (2011), por exemplo, discorrem sobre as bases teóricas e epistemológicas da abordagem dos perfis conceituais - de forma sintética, originalmente o perfil conceitual se distinguiu como um instrumento de análise "que permite relacionar as idéias dos estudantes ao saber escolar e aos conceitos científicos" (Mortimer, 1996, p. 35). De acordo com os autores, as bases epistemológicas dos perfis conceituais não têm qualquer compromisso com o relativismo.

A abordagem dos perfis conceituais é direcionada à pesquisa em Educação em Ciências, ao contrário de outros "instrumentos de análise" caracterizados por uma maior amplitude e utilizados pelas pesquisas em Ciências Humanas e Sociais, de modo geral. Compreende-se que esse é o caso da análise textual discursiva.

Desde a proposição de Moraes (2003) da análise textual discursiva, é possivel identificar a presença de seus procedimentos analíticos em um número considerável de pesquisas publicadas na área de Educação em Ciências, em âmbito nacional ou internacional. Este trabalho não objetiva refletir sobre os possiveis motivos que tornaram a análise textual discursiva tão presente em pesquisas da referida área, apesar de não se restringir a ela, como já se destacou. Ainda assim, cabe registrar que o fato de os seus elaboradores serem pesquisadores em Educação em Ciências pode ter colaborado para o cenário apresentado. Dada a notabilidade das investigações disseminadas na área, que utilizam a análise textual discursiva, julga-se desnecessário apresentar citações pontuais para exemplificá-las.

Nos trabalhos que tomam a própria análise textual discursiva como objeto de estudo e de investigação, a exemplo daqueles de Sousa, Galiazzi e Schmidt (2016), Sousa e Galiazzi (2016), Galiazzi e Ramos (2013), Torres et al. (2008) e Moraes e Galiazzi (2006), não se identificou abordagem explicita a seu respeito que a relacionasse com discussões epistemológicas associadas à possibilidade do conhecimento será o sujeito realmente capaz de apreender o objeto? - à origem do conhecimento - a fonte e o fundamento do conhecimento humano é a razão ou a experiência sensivel? — ou à essência do conhecimento - é o objeto que determina o sujeito ou é o sujeito que determina o objeto? (Hessen, 2003). O trabalho que segue busca ser complementar - portanto não antagônico àqueles de Sousa, Galiazzi e Schmidt (2016) e Sousa e Galiazzi (2016) que já trazem importantes considerações de caráter filosófico concernentes à análise textual discursiva - aliás, se dará no artigo indicativo explícito de tal complementaridade. De modo que, almeja-se assim cooperar para a constituição de um quadro teórico relativo à análise textual discursiva e ao salutar e premente debate concernente a ela, dada a amplitude de pesquisas que a utilizam.

Ante o exposto, o objetivo deste trabalho é analisar, a partir dos textos de Moraes e Galiazzi (2007) e de Moraes (2003), como a análise textual discursiva pode ser caracterizada nas discussões epistemológicas vinculadas à possibilidade do conhecimento. Para tanto, apoiase, principalmente, nas contribuições de Hessen (2003). Defende-se que esse exame pode colaborar na elucidação de pressupostos epistemológicos dos quais a análise textual discursiva se aproxima ou se distancia, favorecendo, assim, a compreensão de quais interlocutores teóricos de análise ela pode se afastar ou se aproximar. Em outras palavras, o exame proposto pode contribuir para pesquisadores em Educação e em Educação em Ciências optarem pela análise textual discursiva, sem, contudo, precisarem reduzi-la puramente a passos procedimentais para análise. Pelo contrário, faz-se necessário buscar, nas pesquisas das respectivas áreas, referenciais - que não precisam se caracterizar obrigatoriamente como referenciais teóricos a priori - coerentes do ponto de vista epistemológico. Como afirmam Santos e Greca (2013), se as metodologias são acompanhadas de premissas epistemológicas, então elas não se encerram em meros procedimentos. As autoras, fundamentadas 
na literatura, apontam que amiúde as pesquisas não explicitam articulações coerentes entre a metodologia escolhida e as outras opções dentro da pesquisa (interlocutores teóricos, metateóricos etc.). O que pode remeter à ideia de que a metodologia pode estar desligada das outras partes constituintes do trabalho de pesquisa. Santos e Greca (2013) ainda chamam atenção para a falta de coerência interna em trabalhos de pesquisa em Educação em Ciências publicados no contexto ibero-americano, com implicações indesejáveis na qualidade do conhecimento produzido nessa área.

O trabalho está organizado de modo a apresentar inicialmente exposições, sobretudo, de Hessen (2003), acerca de questões relacionadas à possibilidade do conhecimento. Em seguida, à luz dessas considerações, se realiza uma análise dos textos de Moraes e Galiazzi (2007) e Moraes (2003) e, por último, apresentam-se implicações dessa análise à pesquisa em Educação e em Educação em Ciências.

\section{Sobre a possibilidade do conhecimento}

Para discutir aspectos relacionados à possibilidade do conhecimento, Hessen (2003) faz uso das seguintes categorias: dogmatismo, ceticismo, subjetivismo e relativismo, pragmatismo e criticismo. É possivel destacar as posições epistemológicas em cada uma das categorias acerca da apreensão do objeto pelo sujeito.

No dogmatismo, o problema do conhecimento não chega a ser, de fato, levantado. Em outros termos, os objetos do conhecimento estariam dados ao sujeito, de maneira que os sujeitos apreendem os objetos, existindo, portanto, a verdade. Para Hessen (2003, p. 29): "Esse ponto de vista é sustentado por uma confiança na razão humana que ainda não foi acometida por nenhuma dúvida". O filósofo destaca que a relação entre sujeito e objeto não parece sequer questionável, uma vez que o conhecimento não estaria associado a tal relação. Não se reconhece uma função mediadora do conhecimento, pelo inverso, os objetos de conhecimento seriam dados. O dogmatismo foi predominante nos primórdios da filosofia grega e foi dos sofistas a primazia de colocar o problema do conhecimento e enfraquecer o dogmatismo na filosofia (Hessen, 2003). Os filósofos que seguem se constituem em críticos do dogmatismo.

O ceticismo, por sua vez, opõe-se ao dogmatismo: o sujeito não seria capaz de apreender o objeto; logo, a verdade não existe. Para Hessen (2003) se, em certa medida, o dogmatismo desconsidera o sujeito, o ceticismo negligencia o objeto, centrando-se em fatores subjetivos do conhecimento humano. O ceticismo radical ou absoluto apresenta uma autocontradição, pois, ao considerar o conhecimento como algo impossivel, expõe um conhecimento de que não há conhecimento. Para o filósofo, o ceticismo também aparece na filosofia moderna, todavia mais específico e não radical e absoluto. Ele chama atenção para o ceticismo ético e o ceticismo metódico, por exemplo, de modo a fortalecer a ideia de que "ceticismo radical ou absoluto é autodestruidor" (Hessen, 2003, p. 33). Seja como for, está posta para o cético a dificuldade de superar a autocontradição:

\begin{abstract}
O cético poderia certamente encontrar uma saída. Poderia indicar o juizo "o conhecimento é impossivel" como duvidoso e dizer: não há nenhum conhecimento, e mesmo isto é duvidoso. Também aqui, porém, há um conhecimento sendo expresso, a saber, o conhecimento de que é duvidoso de que haja conhecimento. Por um lado, portanto, a possibilidade de conhecimento será afirmada pelo cético e, por outro, será posta em dúvida. No fundo, encontramo-nos diante da mesma autocontradição de antes. (Hessen, 2013, p. 34)
\end{abstract}

Em suma, antítese do dogmatismo, o ceticismo colabora para manter o problema do conhecimento, colocando em xeque a confiança do sujeito na razão humana e, ao mesmo tempo, "enredando-se" ao passo que não vê sentido na aspiração ao conhecimento, pois seria impossivel a apreensão efetiva do objeto.

Sobre o subjetivismo e o relativismo, o autor ressalta que, para o primeiro, há a verdade, embora não seja universalmente válida, uma vez que a validade da verdade está restrita ao sujeito 
do conhecimento. Para o segundo, a verdade não é universalmente válida, pois está vinculada a fatores externos ao sujeito - o contexto. Já o pragmatismo, ao abandonar a ideia de verdade, assim como o ceticismo, propõe outro conceito. De acordo com essa posição, verdadeiro "significa o mesmo que útil, valioso, promotor da vida" (Hessen, p. 40). Tal acepção de verdade para o pragmatismo está ligada a uma compreensão de ser humano como um ser prático, com vontades e ativo, em oposição ao um ser humano teórico e pensante. Em outros termos, o intelecto do ser humano não tem a função de favorecer os atos de investigar e conhecer. O intelecto estaria à disposição do seu querer e agir. Ao discorrer a respeito de defensores do pragmatismo, Hessen (2003) vai apontar limitações na associação entre verdade e "ações adequadas e favoráveis à vida". o filósofo assim sintetiza:

O erro fundamental do pragmatismo consiste em não enxergar a esfera lógica. Ele desconhece o valor próprio, a autonomia do pensamento humano. Certamente, por se acharem inseridos na totalidade da vida espiritual humana, o pensamento e conhecimentos estão em conexão estreita com a vida. O que há de bom e valioso no pragmatismo é justamente a referência constante que faz a essa conexão. Essa relação estreita entre conhecimento e vida, porém, não nos deve desencaminhar, instigando-nos a desconsiderar a autonomia do conhecimento e a fazer dele uma simples função vital. Isto só é possivel, conforme mostramos, na medida em que se falsifica o conceito de verdade, ou se nega a verdade. Nossa consciência lógica, porém, protesta contra ambos. (Hessen, 2003, p. 42, grifo do autor)

Expostas as limitações do pragmatismo, Hessen (2003) afirma que tanto o pragmatismo quanto o subjetivismo e o relativismo se aproximam do ceticismo que, como dito, contrapõe-se ao dogmatismo. Assim, o autor apresenta uma posição intermediária entre o dogmatismo e o ceticismo: o criticismo. O ponto de vista do criticismo é a defesa da existência da verdade, embora, ao mesmo tempo, desconfie de qualquer conhecimento determinado. Nas palavras do próprio Hessen, o criticismo:
[...] compartilha com o dogmatismo uma confiança axiomática na razão humana, está convencido de que o conhecimento existe e de que a verdade existe. Enquanto, porém, essa confiança induz o dogmatismo a aceitar de modo, por assim dizer, inconsciente toda afirmação da razão humana e a não reconhecer nenhum limite para a capacidade humana de conhecimento, o criticismo, aproximando-se do ceticismo, junta à confiança no conhecimento humano em geral uma desconfiança com relação a qualquer conhecimento determinado [...]. Por toda parte pergunta sobre os fundamentos, e reclama da razão humana uma prestação de contas. Seu comportamento não é nem cético nem dogmático, mas criticamente inquisidor - um meio termo entre a temeridade dogmática e o desespero cético. (Hessen, 2003, p. 43)

Dentre as categorias, avaliam-se as discussões associadas, sobretudo, ao relativismo, como suscetiveis de contribuir para um exame mais profícuo acerca de pressupostos epistemológicos da análise textual discursiva, de modo que aqui se expandirão as considerações concernentes a essa categoria.

O subjetivismo e o relativismo sofrem de contradição semelhante àquela que atinge o ceticismo. Antes de tudo, Hessen (2003) ressalta que, do ponto de vista filosófico, é uma contradição se referir a uma verdade que não seja universalmente válida, uma vez que a sua validade universal tem fundamento na própria essência da verdade. Na mesma obra, o autor discute também, de forma sistematizada, a essência da verdade, assunto não abordado neste artigo, ainda que necessário, mormente por causa da polissemia que o termo "verdade" assume na pesquisa em Educação e em Educação em Ciências, inclusive com preconceitos e confusões vinculados à sua utilização. A insustentabilidade do subjetivismo e do relativismo pode ser assim explicada:

O subjetivismo se contradiz na medida em que, como questão de fato, reclama para seu juizo "toda verdade é subjetiva" uma validade mais do que subjetiva. Quando o subjetivista formula o seu juizo, certamente não pensa - "isto vale apenas para mim; para os outros, não tem qualquer validade". Se outra pessoa objetasse - "com o mesmo direito com que você diz que toda verdade é subjetiva, eu digo 
que toda verdade tem validade universal" -, ele seguramente não estaria de acordo. Mas isso prova que, como questão de fato, ele atribui validade universal a seu juizo. E faz exatamente por estar convencido de que seu juizo acerta no alvo, de que traduz um estado de coisas objetivo. Na prática portanto, ele pressupõe a validade universal da verdade que nega teoricamente.

O mesmo vale para o relativismo. Se o relativista formula a tese - "toda verdade é relativa" -, está convencido de que essa proposição traduz um estado de coisas objetivo e de que também vale para todo sujeito pensante. (Hessen, 2003, p. 38-39)

Essa contradição interna do relativismo é apontada em várias outras obras de autores contemporâneos, a exemplo de Moser, Mulder e Trout (2009, p. 72), quando se perguntam: "a suposta verdade do relativismo é também relativa?". Eles acrescentam que aqueles que adotam o relativismo podem defender que os critérios usados para "determinar" ou "identificar" o que é verdadeiro se constituam na verdade propriamente dita². Contudo, chamam atenção para a necessidade de diferenciar os critérios definidores acerca do que é verdadeiro e do que é a verdade, fazendo com que essa distinção seja, inclusive, imperativa para garantir a possibilidade do erro. Outra concordância entre Hessen (2003) e Moser, Mulder e Trout (2009) se refere a uma assertiva vigorosa do relativismo, isto é, à ideia de que uma dada interpretação, na qualidade de tradução de um estado de coisas objetivo, pode ser verdade para um sujeito e ser, simultaneamente, falsa para outro. Seria como dizer: "pode ser verdade para mim que a janela está aberta e, ao mesmo tempo, isso ser falso para você". Moser, Mulder e Trout (2009, p. 70, grifo do autor) complementam: "a janela pode me parecer aberta e lhe parecer fechada. Nesta última afirmação [...] é muito claro que a mesma coisa pode assumir aparências diversas para pessoas diferentes [...]. Essa afirmação mais modesta não é a tese relativista".

Acredita-se que se avançou na discussão acerca das categorias associadas à possibilidade do conhecimento elencadas por Hessen (2003)3. inclusive sobre o relativismo. Muitos são os enfoques ao seu respeito com posicionamentos, muitas vezes, controversos. Epistemólogos contemporâneos da ciência se dedicaram ao exame do relativismo, sem necessariamente se restringir às ciências da natureza, e cujas reflexões podem colaborar para entender os limites dessa categoria. É o caso de Popper (1996), por exemplo. Em sua defesa da racionalidade independentemente da concordância com as ideias do autor sobre o tema -, argumenta que o relativismo cultural pode se caracterizar como um problema no processo de aprendizagem entre os individuos envolvidos. O autor complementa que o choque de culturas pode ser igualmente prejudicado quando uma das culturas se considera a priori universalmente superior, ou mesmo, inferior. Quando uma cultura se convence de sua superioridade, e a outra de sua inferioridade, então, a "atitude crítica" de aprender uma com a outra se perde.

Bunge (1991) é outro importante filósofo com posicionamentos antirrelativistas. Bunge (1991) defenderá um realismo 4 ontológico: a realidade existe independentemente do sujeito que conhece. Por conseguinte, critica a ideia de inexistência de uma realidade independentemente de palavras diga-se de passagem, uma compreensão crucial no âmbito de uma análise textual. O estudioso argentino, ao argumentar em favor da construção de um conhecimento sobre uma realidade existente afora do sujeito que conhece, atenta para o caráter social das teorias, sem reduzir o que se conhece a uma construção social. Para Bunge (1991), não é de se estranhar que aqueles descrentes em uma realidade que independe do sujeito e entendedores de que o "mundo inteiro é uma construção social" acreditem, igualmente, na inexistência da verdade. Ou, em uma perspectiva relativista, que compreendam a verdade como algo dependente dos contextos - tese relativista.

\footnotetext{
Na obra citada, os autores utilizam exemplos que ilustram o exposto aqui e que se recomenda a leitura.

A obra original de Hessen (2003) remonta à década de 1920.

O realismo é uma das categorias expostas por Hessen (2003) como resposta para o problema da essência do conhecimento. De acordo com ele, o realismo possui diferentes formas, como o realismo ingênuo e o realismo crítico.
} 
Cumpre registrar que se reconhece a exposição na literatura de certas contribuições do relativismo. De acordo com Boudon (2010) o bom relativismo colaborou à compreensão de que as representações, normas e valores estão condicionados social e culturalmente. Já o relativismo ruim tomou tal compreensão como significado de impossibilidade de haver objetividade nas representações, normas e valores. Assim, segundo o autor, o bom relativismo permite entender o porquê de diferentes intelectuais terem visões variadas a respeito de determinado assunto. Isso estaria relacionado ao fato de estarem inseridos em "contextos sociais e mentais diferentes". De outra parte, o relativismo ruim defende que é desnecessária a compreensão da diversidade de normas e situações - que envolvem aquelas de ordem cultural - concernentes aos seres humanos. A diversidade precisaria ser apenas registrada. Boudon (2010, p. 19) coloca: "Aguada-se ainda o culturalista que se recusaria a julgar do exterior o apedrejamento das mulheres adúlteras ou a condenação à morte devido à conversão religiosa". O autor advoga em favor do afastamento do relativismo ruim, uma vez que esse implica em "perturbação intelectual, moral e política" e finaliza a sua obra assim:

Amanhã a história da luta contra a pobreza, da ampliação geográfica da justiça internacional ou do estado de direito será talvez analisada por nossos bisnetos em termos semelhantes àqueles nos quais se analisa hoje a história da escravidão. Talvez estejamos acerca desses assuntos no ponto em que [...] a impossibilidade de responder de maneira satisfatória às exigências da racionalidade axiológica é percebida como uma fatalidade. (Boudon, 2010, p. 88)

Em suma, Boudon (2010) realça a necessidade de superar a visão binária associada ao universal e ao singular e de refletir a respeito da sobreposição um em relação ao outro.

Neste ponto, é preciso destacar do que não se trata o artigo. Ou seja, não é um trabalho sobre o relativismo à luz de diferentes teóricos. Vários autores têm dedicado livros exclusivos para abordá-lo, até mesmo em suas variações: relativismo cultural, relativismo funcionalista, relativismo cognitivo etc., a exemplo daquele citado de Boudon (2010). De tal sorte, não se tem a pretensão de expandir a discussão a respeito do assunto no momento. Ao mesmo tempo, não será um trabalho que abordará possiveis consequências do relativismo na Educação/ Educação em Ciências, ou na pesquisa nessas áreas. Como exemplo disso, há o trabalho dos autores Della Fonte (2009), Moraes (2009), Harres (2007), Duarte (2006) e Oliveira (2003), esteja-se ou não em sintonia com que expõem.

Face ao exposto, argumenta-se que as categorias expostas por Hessen (2003), em resposta ao problema da possibilidade do conhecimento - mais particularmente o relativismo -, podem colaborar na interpretação de posições epistemológicas na análise textual discursiva, como se apresentará a seguir.

\section{A análise textual discursiva: interpretações epistemológicas}

A análise textual discursiva, na qualidade de um procedimento de análise $/$ método $^{5}$ de análise, constitui-se de três etapas: unitarização, categorização e comunicação. A primeira etapa tem o papel de fragmentar os textos (já existentes ou produzidos a partir de entrevistas etc.) que compõem o corpus em unidades de significado. $\mathrm{Na}$ etapa de categorização essas unidades são agrupadas de acordo com critérios semânticos, de modo a se construir as categorias de análise. Essas categorias podem ser de naturezas distintas: a priori, emergentes ou mistas. As categorias a priori são deduzidas dos fundamentos teóricos da pesquisa, sendo definidas previamente. O papel do pesquisador, em parte, é o de enquadrar as unidades de significado nas categorias. Mas, na pesquisa não existem somente categorias a priori. As categorias podem ser produzidas a partir das unidades de significado em decorrência do

\footnotetext{
5 A expressão "método de análise", em referência à análise textual discursiva, pode ser encontrada em trabalhos que envolvem seus próprios propositores, a exemplo de Galiazzi e Ramos (2013).
} 
processo de unitarização. Esse tipo de categoria é denominado emergente.

De fato, não raramente se identificam pesquisadores menos experientes em métodos de análise qualitativa com interpretações pouco adequadas acerca dessas categorias. Por exemplo, uma das interpretações é a de que a categoria emergente pressupõe uma suposta neutralidade de quem interpreta os fragmentos. Ora, é sabido que as interpretações dos pesquisadores não são neutras. O fato de o pesquisador não ter categorias a priori não significa que ele esteja no vácuo teórico.

Outra possibilidade é a adoção de categorias mistas: categorias selecionadas a priori combinadas com categorias emergentes. Quando o pesquisador opta unicamente pelas categorias a priori, corre o risco de não analisar unidades de significado importantes na compreensão do fenômeno investigado, ou então, de avançar menos do que seria possivel com novidades naquela temática.

A terceira etapa - comunicação - é responsável pela produção do metatexto de análise caracterizado pela ênfase descritiva e interpretativa, ainda que a interpretação seja um aspecto presente na descrição. No próprio processo de unitarização, o investigador interpreta os textos e os fragmentos deles extraidos. Moraes (2003, p. 13), já na proposição da análise textual discursiva, chamava atenção para a relação entre a leitura e a interpretação ao longo do processo analítico: "Todo texto possibilita uma multiplicidade de leituras, leituras essas relacionadas com as intenções dos autores, com os referenciais teóricos dos leitores e com os campos semânticos em que se inserem". Esse posicionamento do autor nos remete às discussões de Hanson (1975), no campo da Filosofia da Ciência, sobre observação e interpretação, as quais podem ser utilizadas, com os devidos cuidados, para sustentar o posicionamento da análise textual discursiva acerca dessa relação.

Hanson (1975) auxilia na compreensão de que o observador neutro se constitui em um mito. Ele defende a tese da inseparabilidade entre a observação e a interpretação. O filósofo da ciência se opõe ao entendimento neopositivista da observação de que o ato de observar e registrar dados sensórios se mantém separado das elaborações intelectuais relacionadas a tais registros. Nessa perspectiva, admite-se que dois cientistas "ideais" fariam as mesmas "observações", sendo que a maneira de proceder diante dessas observações até poderia diferenciálos. No caso da observação visual se poderia afirmar que dois pesquisadores frente a um objeto, nas mesmas circunstâncias, veriam a mesma coisa. Todavia, há muito mais em relação à observação visual do que se pode mencionar por meio da fisiologia da visão. Para Hanson (1975), dois observadores podem se deparar com os mesmos objetos e fenômenos e fazer observações diferentes. O autor complementa: "Isso porque estão OBSERVANDO e não porque esteja impingindo teorias diferentes a dados 'puros': OBSERVAR X É VÊ-LO COMO ISTO OU AQUILO" (p. 129). Em outras palavras, para ele, observar é algo a ser aprendido ou é preciso aprender para observar:

\begin{abstract}
O exame de como os observadores vêem coisas diferentes em dado fenômeno físico permite anotação importante acerca de ocasiões em que eles sustentam estar observando a mesma coisa. Se ver coisas diferentes implica em ter conhecimento diferente, elaborar teorias diferentes e fazer conjecturas diferentes acerca de $X$, então ver a mesma coisa implica compartilhar conhecimento, teorias e conjecturas, acerca de X [...] dois observadores científicos podem defrontar-se com os mesmos dados - utilizar os mesmos enunciados descritivos - e, apesar disso, retirar conclusões diametralmente opostas quanto ao significado do que tiverem diante de si. E isso muito antes de que se inicie o explícito "teorizar" [...]. (Hanson, 1975, p. 136-137)
\end{abstract}

Em suma, Hanson (1975) advoga que a observação e a interpretação não precisam ser conjugadas, pois elas, de fato, não se afastam. Semelhantemente, a leitura e a interpretação também estão casadas. O próprio autor suscita essa correlação ao questionar: "Que faz você neste momento, além de ler estas palavras?" (p. 133). Uma resposta plausivel seria: interpretamos. Se não há 
o mito do observador neutro, não há igualmente o mito do leitor neutro. Cada sujeito lê um texto com os seus conhecimentos. No caso da análise textual discursiva seria problemático o seguinte pressuposto: primeiro, um pesquisador, por meio da leitura, fragmenta os textos que constituem o corpus para, em seguida, e uma vez construida a categorização, passar a interpretar as unidades de significado no processo de comunicação. A interpretação é algo presente no processo de leitura durante a análise textual discursiva. Por exemplo, é comum o próprio pesquisador optar por transcrever entrevistas, obtendo, assim, uma interpretação prévia das informações a serem submetidas de maneira mais formal aos procedimentos da análise textual discursiva.

Compreensões como a de Hanson (1975), de que observadores diferentes podem ter diferentes interpretações dos objetos e fenômenos observados, assim como a de Moraes (2003), de que na leitura de um texto pode haver uma multiplicidade de leituras, não coadunam com as compreensões do subjetivismo ou do relativismo, nos termos expostos por Hessen (2003). Afirmar que a leitura tem caráter subjetivo ou relativo não significa, obrigatoriamente, filiar-se às respectivas categorias, na qualidade de categorias para o problema da possibilidade do conhecimento. A não neutralidade exposta não pode ser confundida com a tese relativista. Hanson (1975) não afirma que toda e qualquer observação é válida, assim como Moraes não defende que toda interpretação é válida a partir de determinada leitura. No caso do filósofo, ele não equipara as interpretações de um pesquisador profissional da área de Física com as de um visitante leigo do laboratório desse pesquisador quanto a aspectos relacionados à Física. Inversamente, destacará que o visitante não pode observar o que o físico observa. No contexto da análise textual discursiva, é preciso registrar o papel da presença das unidades de significado no texto analítico:

A descrição na análise textual qualitativa concretiza-se a partir das categorias construidas no decorrer da análise. Descrever é apresentar as categorias e subcategorias, fundamentando e validando essas descrições a partir de in- terlocuções empiricas ou ancoragem dos argumentos em informações retiradas dos textos [...]. Essa é uma das formas de sua validação. (Moraes \& Galiazzi, 2007, p. 35, grifo do autor)

Afirmar que as produções escritas originadas de uma pesquisa precisam ser validadas é advertir que necessitam ter capacidade descritiva, o que é garantido a partir da validade das categorias e dos argumentos construidos. Essa validade diz respeito à pertinência do que se afirma em relação aos fenômenos investigados, e uma das formas de consegui-la é empregando os depoimentos, falas ou expressões escritas dos sujeitos participantes da pesquisa. (Moraes \& Galiazzi, p. 98-99, grifo do autor)

O exposto de forma reiterada pelos teóricos da análise textual discursiva dá indicativos de que essa proposta analítica se afasta de uma compreensão relativista e subjetivista. Vale lembrar que uma afirmação do relativismo é a de que uma interpretação, enquanto tradução de um estado de coisas objetivo, pode ser uma verdade para um sujeito e, concomitantemente, não ser uma verdade para outro (Moser, Mulder, \& Trout, 2009; Hessen, 2003). De forma oposta, conforme explicitado na análise textual discursiva, as diferentes interpretações que os pesquisadores podem fazer de um mesmo texto não significa que sejam igualmente válidas. Pelo contrário, certas interpretações, ancoradas empiricamente, em comparação a outras, podem ter diferentes hierarquias. Dadas interpretações podem estar associadas, inclusive, a um conhecimento de senso comum - tomando a pesquisa em Educação e em Educação em Ciências é possivel se referir a um senso comum pedagógico.

Outras posições sustentadas pelos teóricos da análise textual discursiva, de que há relação entre o texto e o contexto, não podem ser confundidas também com ideias relativistas. Seria possivel recorrer a interlocutores de outros campos do conhecimento, como Bakhtin (2004), na filosofia da linguagem, para ressaltar tal assertiva, isto é, de que "não se pode esquecer a relação inseparável entre texto e contexto" (Moraes \& Galiazzi, 2007. p. 55), algo que não se caracteriza como um posicionamento relativista, no entendimento do filósofo. Bakhtin (2004) também destacou: "o 
sentido da palavra é totalmente determinado por um contexto. De fato, há tantas significações possiveis quantos contextos possiveis" (Bakhtin, 2004, p. 106). Amorim (2004, 2003) expõe que a crítica da filosofia da linguagem de Bakhtin ao relativismo é algo importante de ser reconhecido. A autora argumenta que a renúncia à ideia de transparência em um texto não significa o abandono da teoria e do trabalho de objetivação e conceituação. Ela complementa:

A polifonia em Ciências Humanas não exime o pesquisador do trabalho de análise. E sabemos que o trabalho do conceito tende necessariamente a uma tradução universalizante da diversidade. Na tensão entre os pólos singularizante e universalizante está, segundo Bakhtin, o desafio e a riqueza das Ciências Humanas e somente uma postura relativista pode querer fugir a essa tensão. (Amorim, 2003, p. 12)

Para ela, é do relativismo que pesquisas em Ciências Humanas precisam se afastar na atualidade, porque do dogmatismo parece já terem se distanciado. Ou seja, para Amorim (2003), o relativismo está muito presente na pesquisa contemporânea na referida área. Diante do exposto, destaca-se que uma interlocução com outros teóricos, como do campo da filosofia da linguagem, por exemplo, pode colaborar com as discussões de caráter epistemológico acerca da análise textual discursiva, de modo a evitar confusões. Em outros termos, uma discussão de natureza epistemológica a respeito da análise textual discursiva não exclui interlocuções com outros campos de conhecimento, como a filosofia da linguagem.

Avalia-se que o apresentado pela análise textual discursiva se afasta igualmente de argumentos subjetivistas e relativistas, na medida em que não reduz o objeto da pesquisa ao modo de se expressar sobre ele. Essa compreensão parece transcender aquela apresentada por Hessen (2003). Moraes e Galiazzi (2007, p. 136-137) expõem:

Finalmente, a partir da convicção da importância de integrar qualidade formal e política, emerge da análise a possibilidade de transformação das realidades investigadas. As aprendizagens concretizadas, expressas nos metatextos, organizados em torno de teses e argumentos do pesquisador. podem constituir-se em formas de intervenção nos discursos nos quais os textos submetidos à análise se inserem. Nisso situa-se a qualidade politica das análises e de seus produtos.

Assim, uma análise textual discursiva rigorosa pode garantir a qualidade formal dos resultados da pesquisa. A qualidade política, entretanto, depende dos pressupostos assumidos pelo pesquisador em seu trabalho, especialmente o assumir como sujeito histórico, capaz de intervir nos discursos no sentido de sua reconstrução.

[...] é um modo de intervir na realidade. assumindo-se o pesquisador como sujeito histórico, capaz de participar na reconstrução de discursos existentes (grifo do autor).

O fato de o método proposto se referir a uma realidade que independe do pesquisador pode ser interpretado como uma sinalização de que se tem como um pressuposto a existência de uma verdade que se relaciona com uma dimensão objetiva. Isso não significa defender uma visão positivista de que é possivel escrever sobre os objetos investigados de modo a registrá-los da maneira como realmente são. O contrário seria um retrocesso, com base nas discussões epistemológicas contemporâneas.

O argumento apresentado aqui possui certa coerência com as discussões expostas por Sousa, Galiazzi e Schmidt (2016) e Sousa e Galiazzi (2016) ao associarem a hermenêutica filosófica de Hans-Georg Gadamer aos pressupostos da análise textual discursiva. De acordo com Silva (2008), a fenomenologia hermenêutica de Gadamer se afasta do relativismo, por exemplo, na medida em que o filósofo defende ideias que valorizam a comunicação e a discussão racional entre horizontes variados. O autor aponta, entre outros aspectos, que Gadamer também buscou critérios para fazer a distinção entre interpretações adequadas e inadequadas, de maneira a enfrentar o relativismo ou o anarquismo hermenêutico.

Compreende-se que o apresentado até o momento tem implicações às pesquisas que se apoiam na análise textual discursiva para conduzir o exame das informações qualitativas. Trata-se a seguir desse aspecto. 
À guisa de encerramento: implicações à pesquisa em Educação e em Educação em Ciências

As considerações a respeito da análise textual discursiva a distanciam de uma perspectiva relativista com implicações às pesquisas que a adotam. Essas consequências estão associadas ao reconhecimento de que, embora esse método seja constituído por procedimentos, tem uma sustentação teórica com determinadas caracteristicas epistemológicas que, de acordo com o exposto até então, não convém negligenciá-las. Uma dessas implicações é o fato de as pesquisas em Educação e em Educação em Ciências que adotam esse procedimento - as quais são cada vez maiores, bastando, para isso, consultar os periódicos nacionais nos últimos anos -, precisarem se apoiar também em interlocutores teóricos que se afastam de uma perspectiva relativista. E, ainda, que investigações não tenham um referencial teórico explícito, aspecto plenamente admissivel, como no caso daquelas com categorias de análise emergentes, essas investigações se manifestarão teorizações que necessitarão estar em dissonância com posturas relativistas.

Inclusive, encontram-se na literatura estudos acerca de articulações entre a análise textual discursiva com determinados referenciais teóricos que se distanciam de fundamentações relativistas. Um exemplo é o trabalho de Torres et al. (2008), anteriormente citado. Os autores desenvolvem uma reflexão sobre a possibilidade de se obter temas estruturadores de currículos críticos através da investigação temática, nos termos propostos por Freire (2005), mas articulada à análise textual discursiva (Moraes, 2003). Sinaliza-se essa articulação como um exemplo coerente de aproximação que se distancia de uma perspectiva relativista, pois se identificam, na compreensão de Paulo Freire quanto à educação, visões em desarmonia com posturas relativistas, como as que tendem colocar, como equivalentes hierárquicos, conhecimentos de senso comum com conhecimentos sistematizados. Na visão relativista ensinar conhecimentos sistematizados vinculados a conhecimentos científicos e tecnológicos nos processos educativos não precisaria ser um objetivo do educador/docente, posto que a validade de cada conhecimento estaria relacionada com o contexto. Segue um exemplo de ideia do reconhecido educador brasileiro acerca desse tipo de compreensão relativista:

(...) Educar e educar-se, na prática da liberdade, não é estender algo desde a "sede do saber", até a "sede da ignorância" para "salvar", com este saber, os que habitam nesta.

Ao contrário, educar e educar-se, na prática da liberdade, é tarefa daqueles que sabem que pouco sabem - por isto sabem que sabem algo e podem assim chegar a saber mais - em diálogo com aqueles que, quase sempre, pensam que nada sabem, para que estes, transformando o seu pensar que nada sabem em saber que pouco sabem, possam igualmente saber mais. (Freire, 1977, p. 25. grifo do autor)

O exposto é um indicativo de que Freire (1977) possui uma compreensão em desarmonia com o relativismo - para o qual a validade da verdade está relacionada ao contexto. Se não fosse assim, não haveria a necessidade de se defender veementemente a apropriação de conhecimentos sistematizados. Ainda nessa direção encontra-se o trabalho de Alves e Silva (2015) que, ao investigarem a manifestação de obstáculos gnosiológicos na escolha de conteúdos para currículos críticos de ciências, realizaram entrevistas semiestruturadas, cuja análise considerou a análise textual discursiva e os critérios de identificação de falas significativas.

Aponta-se, assim, a importância de os pesquisadores em Educação e em Educação em Ciências reconhecerem os vieses epistemológicos dos referenciais teórico-metodológicos que deverão escolher para as suas investigações. Expôs-se aqui um exame que identifica um distanciamento da análise textual discursiva com posturas relativistas, e que há coerência no fato de os pesquisadores supracitados buscarem referenciais teóricos em harmonia com essa característica, própria do referido método de análise. Com isso, não se pretende ir à contramão do pluralismo teórico nas investigações que o utilizam, pelo contrário. 
Entende-se que a análise textual discursiva, na qualidade de um procedimento analítico aberto, e conforme exposto por Moraes e Galiazzi (2007), é suscetivel a contribuições que possam favorecer a sua transformação, desde que sejam coerentes com as suas fundamentações, explicitas ou tácitas. Nisso fica subentendido de que não "vale tudo" - expressão conhecida nas discussões epistemológicas e vinculadas a ideias relativistas. Entende-se que o exame realizado favorece uma aproximação dos pressupostos da análise textual discursiva ao criticismo, nos termos apresentados por Hessen (2003), isto é, aposta na existência da verdade e, simultaneamente, desconfia de qualquer conhecimento determinado.

As colocações aqui expostas acerca das considerações de natureza epistemológicas a respeito da análise textual discursiva não têm a pretensão de concluir o assunto, mas de continuá-lo.

\section{Referências}

Alves, A. H. B., \& Silva, A. F. G. (2015). Manifestações de obstáculos gnosiológicos para a seleção de conteúdos na implementação de um currículo crítico em ciências naturais. Alexandria: Revista de Educação em Ciência e Tecnologia, 8(1), 181-207. https://doi. org/10.5007/1982-5153.2015V8n1p181

Amorim, M. (2003). A contribuição de Mikhail Bakhtin a tripla articulação ética, estética e epistemológica. In M. T. Freitas, S. Kramer, \& S. Jobim e Souza. Ciências Humanas e pesquisa: leituras de Mikhail Bakhtin (pp. 11-25). Cortez

Amorim, M. (2004). O pesquisador e seu outro: Bakhtin nas Ciências Humanas. São Paulo: Musa.

Bakhtin, M. (Volochinov, V. N.). (2004). Marxismo e Filosofia da Linguagem: problemas fundamentais do método sociológico da ciência da linguagem ( $11^{\text {a }}$ ed). Hucitec. https://doi.org/10.1590/2176-457336646

Boudon, R. (2010). O relativismo. Edições Loyola.

Bunge, M. (1991). Una caricatura de la ciencia: la novísima sociologia de la ciencia. Interciencia, 16(2), 69-77.

Della Fonte, S. S. (2009). Heidegger, o pós-moderno e a educação. Educação \& Realidade, 34(1), 191-209.

Duarte, N. (2006). A contradição entre universalidade da cultura humana e o esvaziamento das relações sociais: por uma educação que supere a falsa escolha entre etnocentrismo ou relativismo cultural. Educação e Pesquisa, 32(3), 607-618. https://doi. org/10.1590/s1517-97022006000300012

Freire, P. (1977). Extensão ou comunicação? Paz e Terra.
Freire, P. (2005). Pedagogia do Oprimido. $40^{\mathrm{a}}$ ed. Paz e Terra.

Galiazzi, M. C., \& Ramos, M. (2013). Aprendentes do aprender: um exercicio de análise textual discursiva. Indagatio Didactica, 5(2), p. 868-883.

Hanson, N. R. (1075) Observação e interpretação. In E Nagel, \& S. M. Sidney. Filosofia da ciência (pp. 125138). Cultrix.

Harres, J. B. S. (2007). Relativismo (moderado) em sala de aula análise de um caso na disciplina de metodologia do ensino superior. In R. M. R. Borges (Org.). Filosofia e história da ciência no contexto da educação em ciências: vivências e teorias (pp. 141-167). EDIPUCRS. https://doi.org/10.1590/s1516-73132003000100005

Hessen, J. (2003). Teoria do conhecimento. $2^{\mathrm{a}}$ ed. Martins Fontes.

Moraes, M. C. M. (2009). A teoria tem consequência: indagações sobre o conhecimento no campo da educação. Educação \& Sociedade, 30(107), 585-607. https://doi.org/10.1590/s0101-73302009000200014

Moraes, R. (2003). Uma tempestade de luz: a compreensão possibilitada pela análise textual discursiva. Ciência \& Educação, 9(2), 191-211. https://doi. org/10.1590/s1516-73132003000200004

Moraes, R., \& Galiazzi, M. C. (2006). Análise textual discursiva: processo reconstrutivo de múltiplas faces. Ciência \& Educação, 12(1), 117-128. https://doi. org/10.1590/s1516-73132006000100009

Moraes, R., \& Galiazzi, M. C. Análise Textual Discursiva. Editora Unijui, 2007.

Moser, P. K., Mulder, D. H., \& Trout, J. D. (2009). A teoria do conhecimento: uma introdução temática. $2^{a}$ ed. Editora WMF: Martins Fontes.

Mortimer, E. F. (1996). Construtivismo, mudança conceitual e o ensino de ciências: para onde vamos? Investigações em Ensino de Ciências, 1(1), 20-39.

Mortimer, E. F., Scott, P., \& El-Hani, C. N. (2011). Bases teóricas e epistemológicas da abordagem dos perfis conceituais. Técne, Episteme e Didaxis, (30), p. 111-125. https://doi.org/10.17227/ted.num30-1102

Oliveira, M. B. (2003). Considerações sobre a neutralidade da ciência. Trans/Form/Ação, 26(1), 161-172.

Popper, K. (1996). O mito do contexto: uma defesa da ciência e da racionalidade. Edições 70.

Santos, F. M. T., \& Greca, I. M. (2013). Metodologias de pesquisa no ensino de ciências na América Latina: como pesquisamos na década de 2000. Ciência \& Educação, 19(1), 15-33. https://doi.org/10.1590/ S1516-73132013000100003

Silva, R. S. (2008). O problema do relativismo em Heidegger e Gadamer. Investigaciones fenomenológicas (6), 283-297. https://doi.org/10.5944/rif.6.2008.5514 
Sousa, R. S., Galiazzi, M. C., \& Schmidt, E. B. (2016). Interpretações fenomenológicas e hermenêuticas a partir da análise textual discursiva: a compreensão em pesquisas na educação em ciências. Revista Pesquisa Qualitativa, 4(6), 311-333. https://doi. org/10.1590/1516-731320180030016

Sousa, R. S., \& Galiazzi, M. C. (2016). Compreensões acerca da hermenêutica na análise textual discursiva: marcas teórico-metodológicas à investigação. Contexto \& Educação, (31), 33-55. https://doi. org/10.21527/2179-1309.2016.100.33-5.

Torres, J. R., Gehlen, S. T., Muenchen, C., Gonçalves, F. P., Lindemann, R. H., \& Gonçalves, F. J. F. (2008). Resignificação curricular: contribuições da investigação temática e da análise textual discursiva. Revista Brasileira de Pesquisa em Educação em Ciências, 8(2), 1-13. https://doi.org/10.28976/1984-2686rbpec2018181239

\section{Fábio Peres Gonçalves}

Mestre e Doutor em Educação Científica e Tecnológica pela Universidade Federal de Santa Catarina (UFSC), Florianópolis, SC, Brasil. Professor Associado da Universidade Federal de Santa Catarina (UFSC, Florianópolis, SC, Brasil).

\section{Endereço para correspondência}

Fábio Peres Gonçalves

R. Eng. Agronômico Andrei Cristian Ferreira, s/n

Trindade, 88040900

Florianópolis, SC, Brasil 